\title{
The importance of tissue environment surrounding the tumor on the development of cancer cachexia
}

\author{
FUMIHIRO CHIBA $^{1}$, KUNIYASU SODA $^{1,2}$, SHIGEKI YAMADA $^{3}$, YUKA TOKUTAKE ${ }^{4}$, \\ SHIGERU CHOHNAN $^{5}$, FUMIO KONISHI ${ }^{1}$ and TOSHIKI RIKIYAMA ${ }^{1}$ \\ ${ }^{1}$ Department of Surgery, ${ }^{2}$ Cardiovascular Research Institute, and ${ }^{3}$ Department of Pathology, Saitama Medical Center, \\ Jichi Medical University, Omiya, Saitama City, Saitama 330-8503; ${ }^{4}$ Department of Applied Life Science, \\ United Graduate School of Agricultural Science, Tokyo University of Agriculture and Technology, \\ Fuchu-shi, Tokyo 183-8538; ${ }^{5}$ Department of Bio-resource Science, Ibaraki University \\ College of Agriculture, Ami-cho, Inashiki-gun, Ibaraki 300-0393, Japan
}

Received September 3, 2013; Accepted October 16, 2013

DOI: 10.3892/ijo.2013.2180

\begin{abstract}
The relationship between host factors and cancer cachexia was investigated. A single cell clone (clone 5 tumor) established from colon 26 adenocarcinoma by limiting dilution cell cloning methods was employed to eliminate the inoculation site-dependent differences in the composition of cell clones. Clone 5 tumor did not provoke manifestations of cancer cachexia when inoculated in subcutaneous tissue. However, when inoculated in the gastrocnemius muscle, the peritoneal cavity or the thoracic cavity of CD2F1 male mice, typical manifestations of cancer cachexia were observed in all groups of mice with intergroup variations. The blood levels of various cytokines, chemokines and hormones were increased but with wide intergroup variations. Analyses by stepwise multiple regression models revealed that serum interleukin-10 was the most significant factor associated with manifestations of cancer cachexia, suggesting the possible involvement of mechanisms similar to cancer patients suffering cancer cachexia. White blood cells, especially neutrophils, seemed to have some roles on the induction of cancer cachexia, because massive infiltrations and an increase in peripheral blood were observed in cachectic mice bearing clone 5 tumors. The amount of malonyl-CoA in liver correlated with manifestations of cancer cachexia, however the mRNA levels of spermidine/spermine N-1 acetyl transferase (SSAT) (of which overexpression has been shown to provoke manifestations similar to cancer cachexia) were not necessarily associated with cancer cachexia. These data suggest that the induction
\end{abstract}

Correspondence to: Dr Kuniyasu Soda, Saitama Medical Center, Jichi Medical University, 1-847 Amanuma, Omiya, Saitama City, Saitama 330-8503, Japan

E-mail: soda@jichi.ac.jp

Key words: cancer cachexia, colon 26 adenocarcinoma, cytokine, spermidine/spermine $\mathrm{N}-1$ acetyl transferase, malonyl-CoA, neutrophil of cancer cachexia depends on the environment in which the tumor grows and that the infiltration of host immune cells into the tumor and the resultant increase in inflammation result in the production of cachectic factors, such as cytokines, leading to SSAT activation. Further, multiple factors likely mediate the mechanisms of cancer cachexia. Finally, this animal model was suitable for the investigation of the mechanisms involved in cachexia of cancer patients.

\section{Introduction}

Cancer cachexia is a serious problem that affects the majority of the cancer patients $(1,2)$. The characteristics of cancer cachexia are appetite loss, decrease in body weight (BW) decline in storage fat and muscle weights, and deteriorations of nutrition, water, and electrolyte status. In addition, cancer cachexia is associated with poor prognosis, diminished quality of life, and obstacles to cancer treatment (3). Therefore, it is very important to establish a therapeutic strategy for cancer cachexia in order to improve patient quality of life and outcomes. However, the mechanisms underlying cancer cachexia have not been fully elucidated, likely because many factors (including many cytokines and hormones) are involved in the pathogenesis of this condition $(4,5)$.

Some studies have reported that the tumor characteristics play a major role in the pathogenesis of cancer cachexia, while host factors play a minor role $(6,7)$. However, the fact that cancer cachexia develops in the majority of end-stage cancer patients $(3,8)$ but not in patients with certain types of cancer, suggests that the tumor environment may play a larger role. In addition, cachexia-inducing factors, such as various cytokines and hormones $(4,5)$, are produced both by cancer cells and host cells. Using colon 26 murine adenocarcinoma cells, we previously demonstrated that the host's immune function plays an important role in the development of cancer cachexia (9-12).

Tumor cells are comprised of many different kinds of cells. The inoculation of tumor cells provokes a reaction by the host cells, resulting in a selection of tumor cells. Indeed, inoculation of original colon 26 in different sites results in different 
composition of tumor cells, and the selection of cancer cells in response to the host environment results in different clinical manifestations (13). Even when tumor cells are inoculated in nude mice with an immunological deficit, the metastatic capacity of the established tumor varies according to the site of the tumor $(14,15)$.

The present study investigated the relationship between tumor environment and cancer cachexia. In order to exclude the difference of tumor cell type grown in the inoculated site after selection by the immune system, a single cell clone (clone 5 of colon 26 adenocarcinoma) was employed. Clone 5 tumor was established by the limiting dilution method; i.e., it was established from a single cell of colon 26 adenocarcinoma (16).

\section{Materials and methods}

Tumor cells. Clone 5 cell, a single-cell clone established from colon 26 adenocarcinoma by the limiting dilution cell cloning method, was employed. Unlike original colon 26, clone 5 does not provoke any symptoms and signs of cancer cachexia in mice when inoculated in the subcutaneous tissues $(10,16)$. Clone 20 cell, another subclone of colon 26, with a potent cachexia-inducing capacity when inoculated in subcutaneous tissues, was also used.

Cells were seeded at a density of $5 \times 10^{5}$ cells $/ \mathrm{ml}$ in $\mathrm{T} 75$ flasks (75 $\mathrm{cm}^{2}$, Iwaki Glass, Tokyo, Japan) with RPMI-1640 containing $10 \%$ heat-inactivated fetal bovine serum (FBS) (Gibco, Grand Island, NY, USA) and incubated at $37^{\circ} \mathrm{C}$ in a humidified $5 \% \mathrm{CO}_{2}$ atmosphere until they grew to sub-confluence. They were then trypsinized and re-suspended in Hanks' balanced salt solution (Gibco) at a density of $5 \times 10^{5}$ cells $/ \mathrm{ml}$, and $0.2 \mathrm{ml}$ of cell suspension containing $10^{6}$ cells was inoculated either in the subcutis, gastrocnemius muscle, peritoneal cavity, or thoracic cavity.

For determination of cytokine levels in the cell lysate and conditioned medium, $1 \times 10^{6}$ cells in conditioned medium were centrifuged at $500 \mathrm{x}$ g for $5 \mathrm{~min}$ at $4^{\circ} \mathrm{C}$. The conditioned medium was collected and stored at $-80^{\circ} \mathrm{C}$ until the cytokine assay was performed. The cells were re-suspended with phosphatebuffered saline (PBS). After removal of PBS by centrifugation, the cells were suspended in Procarta lysis buffer (Panomics, Inc., Fremont, CA, USA, from Veritas, Tokyo, Japan) for $5 \mathrm{~min}$ on ice. After centrifugation at $19,100 \times \mathrm{g}$ for $10 \mathrm{~min}$ at $4^{\circ} \mathrm{C}$, the supernatant was collected. The supernatants were stored at $-80^{\circ} \mathrm{C}$ until the cytokine assay was performed.

Animals. The experimental design was approved by the Institutional Review Board of Jichi Medical University, and all animal procedures followed the Principles of Laboratory Animal Care. Seven-week-old male CD2F1 (BALB/c x DBA/2 F1) mice were purchased from Charles River Japan (Atsugi, Kanagawa, Japan). Groups of four mice were housed in a cage placed in a temperature-controlled $\left(22^{\circ} \mathrm{C}\right)$ room with high efficacy particulate arresting (HEPA; $0.3 \mu \mathrm{m}$ ) filtered air supply and were kept under a 12-h light/12-h dark diurnal cycle. Prior to the experiments, mice were fed ad libitum with standard Rodent Laboratory Chow (Nippon Bio-Supply, Tokyo, Japan) so as to become acclimated to experimental conditions. After allowing 1 week of acclimation to the environment, 8-week-old mice were randomly assigned to one of six different groups: i) mice bearing clone 5 subcutaneously in the right flank (C5 Cut), ii) mice bearing clone 5 in the left gastrocnemius muscle (C5 Mus), iii) mice bearing clone 5 in the peritoneal cavity (C5 Per), iv) mice bearing clone 5 in the thoracic cavity (C5 Tho), v) non-tumor-bearing mice (NTB), and vi) mice bearing clone 20 subcutaneously in the right flank (C20 Cut). Body weight and consumption of food and water were measured every day around 4 p.m.

Blood sampling and extirpation of tumors and organs. Blood was collected from the right atrium of mice under profound pentobarbital $(60 \mu \mathrm{g} / \mathrm{g} \mathrm{BW})$ anesthesia at 14 days after tumor inoculation. The right gastrocnemius muscle and epididymal fat pads were extirpated and weighed while wet. Inoculated tumors were extirpated, and $10 \mathrm{mg}$ of tumor was homogenized in $300 \mu \mathrm{l}$ of Procarta lysis buffer (Panomics) with protease inhibitors and centrifuged at $19,100 \mathrm{x}$ g for $10 \mathrm{~min}$ at $4^{\circ} \mathrm{C}$. Supernatant was stored at $-80^{\circ} \mathrm{C}$ until the cytokine assay was performed. For histological and immunohistochemical evaluation, extirpated tumors were stored at $-80^{\circ} \mathrm{C}$ until evaluation.

For assessment of blood cell count, $300 \mu \mathrm{l}$ of the obtained blood was treated with EDTA. Blood cells were counted using a clinical auto-analyzer at a clinical laboratory institute (Japan Pet Life Co., Ltd., Tokyo, Japan). Plasma was obtained from blood treated with heparin. The serum was collected in MiniCollect (Sekisui Chemical Co., Ltd., Tokyo, Japan). Blood samples were centrifuged at $5,000 \mathrm{x} \mathrm{g}$ for $10 \mathrm{~min}$ at $20^{\circ} \mathrm{C}$ to separate plasma or serum from blood cells. Plasma and serum were used for the measurement of hormones via a clinical auto-analyzer at a clinical laboratory institute (SRL, Inc., Tokyo, Japan). The serum was stored at $-80^{\circ} \mathrm{C}$ until the cytokine assay was performed.

Serum amyloid A (SAA) was measured by enzyme-linked immunosorbent assay (ELISA) methods as described in a previous report $(17,18)$. A plastic 96 -well microtiter plate was coated with the monoclonal antibody diluted in PBS overnight at $37^{\circ} \mathrm{C}$ and then blocked with $1 \%$ bovine serum albumin (BSA) in PBS for $2 \mathrm{~h}$ at $37^{\circ} \mathrm{C}$. The mouse serum, diluted more than 1:100 in BSA-PBS containing $0.05 \%$ Tween-20, was added to the plates and allowed to react for $2 \mathrm{~h}$ at $37^{\circ} \mathrm{C}$. The plate was washed and then incubated with a peroxidase-conjugated secondary antibody, clone BI-2, diluted in $1 \%$ BSA-PBS containing $0.05 \%$ Tween-20 for $1 \mathrm{~h}$ at $37^{\circ} \mathrm{C}$. After a final wash, color was developed in ortho-phenyldiamine and read at $490 \mathrm{~nm}$.

Measurement of cytokine levels. Procarta Cytokine Assay kit (Panomics) was used for cytokine determination. After incubation with antibody-conjugated beads, detection antibodies and streptavidin-phycoerythrin complexes, samples were assessed by a Luminex 100 instrument (Bio-Rad, Hercules, CA, USA). The cytokines examined were as follows: interleukin (IL)-1 $\beta$, IL-6, IL-10, tumor necrosis factor (TNF)- $\alpha$, interferon (IFN)- $\gamma$, leukemia inhibitory factor (LIF), granulocyte macrophage colony-stimulating factor (GM-CSF), monocyte chemotactic protein (MCP)-1, macrophage inflammatory protein (MIP)-1 $\alpha$ and vascular endothelial growth factor A (VEGF-A). A standard curve for sample cytokine concentration determination was used. Cytokine concentrations in tumor homogenates 
were corrected relative to protein concentrations measured by the Lowry protein assay.

Real-time PCR. Expressions of spermidine/spermine $\mathrm{N}-1$ acetyl transferase (SSAT) in murine liver were evaluated by real-time PCR. Total RNA was extracted from the homogenized liver tissues using the Illustra RNAspin Mini RNA Isolation kit (GE Healthcare Biosciences, Little Chalfont, UK), and the quality of RNA was assessed using a Bioanalyzer 2100 (Agilent Technologies, Santa Clara, CA, USA) according to the manufacturer's instructions. Single-stranded cDNA from total RNA was synthesized using a High Capacity RNA-tocDNA kit (Applied Biosystems, Carlsbad, CA, USA).

The PCR reactions were performed on ABI PRISM 7900 HT sequence detection system (Applied Biosystems) in a total volume of $50 \mu \mathrm{l}$, containing the appropriate amount of SYBR Premix Ex Taq (Takara Bio, Inc., Otsu, Japan), cDNA template and each primer. Thermal cycling conditions were: $95^{\circ} \mathrm{C}$ for $10 \mathrm{sec}$, followed by 40 cycles of $95^{\circ} \mathrm{C}$ for $5 \mathrm{sec}$ and $60^{\circ} \mathrm{C}$ for $34 \mathrm{sec}$. A melt curve was generated after amplification, starting at $95^{\circ} \mathrm{C}$ for $15 \mathrm{sec}$, followed by $60^{\circ} \mathrm{C}$ for $1 \mathrm{~min}$ and then $95^{\circ} \mathrm{C}$ for $15 \mathrm{sec}$. All reactions were run in duplicate. The Sequence Detection System (SDS2.1) software and the external standard curves were used for analysis. Transcript levels of glyceraldehyde-3-phosphate dehydrogenase (GAPDH) were utilized as an internal control. Primers used were as follows: SSAT primers (Invitrogen, Carlsbad, CA, USA): 5'-ATCTAAGCCAGGTTGCAATGA-3' (forward), 5'-GCACTCCTCACTCCTCTGTTG-3' (reverse). GAPDH primers (Invitrogen): 5'-TGTGTCCGTCGTGGATCTGA-3' (forward), 5'-TTGCTGTTGAAGTCGCAGGAG-3' (reverse).

Western blotting. For the measurement of acetyl-CoA carboxylase (ACC), $30 \mathrm{mg}$ of liver in $500 \mu \mathrm{l}$ of lysis buffer [RIPA buffer; Cell Signaling Technology, Beverly, MA, USA: $20 \mathrm{mM}$ Tris- $\mathrm{HCl}$ (pH 7.5), $150 \mathrm{mM} \mathrm{NaCl}, 1 \mathrm{mM} \mathrm{Na}{ }_{2}$ EDTA, $1 \mathrm{mM}$ ethylene glycol tetraacetic acid, $1 \%$ nonyl phenoxypolyethoxylethanol-40, 1\% sodium deoxycholate, $2.5 \mathrm{mM}$ sodium pyrophosphate, $1 \mathrm{mM} \beta$-glycerophosphate, $1 \mathrm{mM}$ $\mathrm{Na}_{3} \mathrm{VO}_{4}, 1 \mu \mathrm{g} / \mathrm{ml}$ leupeptin] with $1 \mathrm{mM}$ phenylmethylsulfonyl fluoride (PMSF) was homogenized and then sonicated three times for $10 \mathrm{sec}$ on ice. After removing insoluble material by centrifugation at $14,000 \times \mathrm{g}$ for $10 \mathrm{~min}$, the total amount of protein was quantified using the Bradford protein assay (Bio-Rad Protein Assay kit; Bio-Rad). Equal amounts of total protein were subjected to SDS-PAGE and then transferred to polyvinylidene difluoride membrane (PVDF) (GE Healthcare Bio-Sciences). The PVDF membrane was blocked with $5 \%$ skim milk in Tris-buffered saline with $0.1 \%$ Tween-20 (TBS-T) for $3 \mathrm{~h}$ at room temperature and then washed two times with TBS-T. The membrane was incubated with anti-acetyl CoA carboxylase antibody (1:200; Cell Signaling Technology) in TBS-T containing 5\% BSA and with antimouse $\beta$-actin antibody (1:3,000; Cell Signaling Technology) in TBS-T containing $5 \%$ skim milk at $4^{\circ} \mathrm{C}$ overnight. The membrane was subsequently rinsed three times and incubated with a horseradish peroxidase (HRP)-conjugated secondary antibody (1:3,000; GE Healthcare) in TBS-T containing $5 \%$ skim milk for $1 \mathrm{~h}$ and then rinsed three times. Finally, protein bands were detected by enhanced chemiluminescence
(ECL Prime; GE Healthcare) and quantified by densitometry using Image $\mathbf{J}$ software.

Malonyl-CoA measurement. Murine livers were weighed and homogenized with a 4-fold weight of $0.3 \mathrm{M} \mathrm{H}_{2} \mathrm{SO}_{4}$ for $10 \mathrm{~min}$ on ice. The supernatants obtained by centrifugation at $10,000 \mathrm{x} \mathrm{g}$ for $10 \mathrm{~min}$ were adjusted to a $\mathrm{pH} 6.5$ on ice using $1 \mathrm{M}$ Tris $5 \% \mathrm{v} / \mathrm{v}$.

The measurement of malonyl-CoA was performed as described previously (malonyl-CoA:acetyl-CoA cycling procedures) $(19,20)$. Briefly, acetyl-CoA in tissue extract was removed by $2 \mu \mathrm{l}$ of citrate synthase with $100 \mathrm{mM}$ oxaloacetic acid, distilled water and cycling buffer $[500 \mathrm{mM}$ Tris- $\mathrm{HCl}$ (pH 7.2) containing $100 \mathrm{mM} \mathrm{MgSO}-7 \mathrm{H}_{2} \mathrm{O}$ and $10 \mathrm{mM}$ 2-mercaptoethanol]. Then, the cycling reaction was initiated by adding $50 \mathrm{mM}$ malonate with $10 \mathrm{mM}$ ATP and $1.0 \mathrm{U}$ of malonate decarboxylase followed by the addition of $1.0 \mathrm{U}$ of acetate kinase. Next, 2.5 M neutralized hydroxylamine was added, and final concentrations of $10 \mathrm{mM}$ ferric chloride dissolved in $25 \mathrm{mM}$ trichloroacetic acid and $1 \mathrm{M} \mathrm{HCl}$ were added. The absorbance of the end product was measured using a spectrophotometer (Ultraspect 3100 Pro, Amersham Biosciences, Buckinghamshire, UK). A standard curve was created using purified malonyl-coenzyme A (Sigma, St. Louis, MO, USA).

Histological and immunohistochemical analysis. Tumor tissues were fixed in $10 \%$ formaldehyde and dehydrated in ethanol and xylene, embedded in paraffin and then cut into serial $3-\mu \mathrm{m}$ sections. The sections were deparaffinized in xylene, hydrated gradually through graded ethanol and then transferred to PBS. One of the sections was stained with hematoxylin and eosin (H\&E), and histological evaluations were conducted by two pathologists and their evaluations were then peer reviewed.

For immunohistochemical analysis, the sections were placed in a container with $10 \mathrm{mM}$ sodium citrate buffer and $0.01 \%$ EDTA and heated at $95^{\circ} \mathrm{C}$ for $30 \mathrm{~min}$ for antigenic retrieval. The sections were treated with $1 \%$ hydrogen peroxide in methanol to quench the endogenous peroxidase activity for 15 min followed by blocking in $10 \%$ normal rabbit serum with $1 \% \mathrm{BSA}$ in PBS for $2 \mathrm{~h}$ at room temperature. The sections were incubated with rat monoclonal anti-neutrophil antibody (1:100; NIMP-R14; Abcam, Cambridge, MA, USA) or rat monoclonal anti-F4/80 antibody (1:100; BM8; Abcam) overnight at $4^{\circ} \mathrm{C}$ in a humidified chamber. After being washed with PBS, the slides were treated with rabbit anti-rat biotinylated secondary antibodies (1:200; Vector Laboratories, Burlingame, CA, USA), and then an $\mathrm{ABC}$ horseradish peroxidase reagent (Vectastain Elite ABC kit; Vector Laboratories) for $30 \mathrm{~min}$ at room temperature. Neutrophils and macrophages were visualized using the Peroxidase Substrate kit (ImmPACT DAB; Vector Laboratories) after incubation for $7 \mathrm{~min}$. The sections were lightly counterstained with Mayer's hematoxylin. According to color sampling method (21), a quantitative assay for immunohistochemistry was performed using Image $\mathbf{J}$ software. Six fields were examined at x40 magnification and analyzed.

Statistical analysis. Data are expressed as the mean \pm standard deviation (SD). All statistical analyses were performed 
A

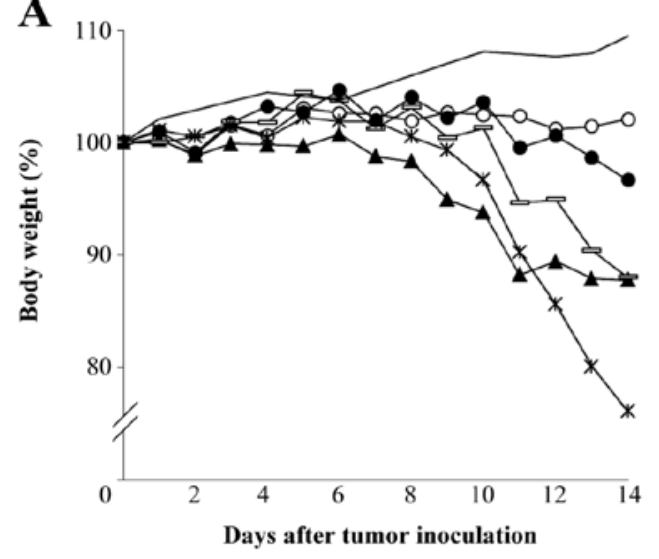

C

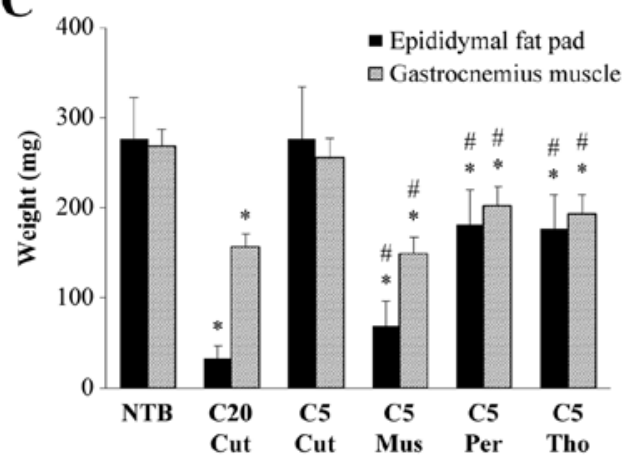

B
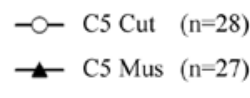

$\rightarrow$ C5 Per $\quad(n=25)$

$\Longrightarrow$ C5 Tho $(\mathrm{n}=24)$

- NTB $\quad(\mathrm{n}=13)$

* C20 Cut $(\mathrm{n}=30)$

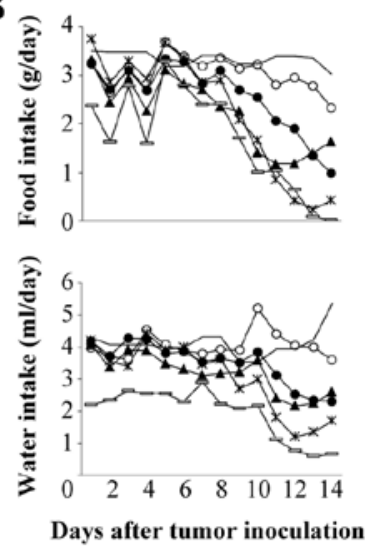

D

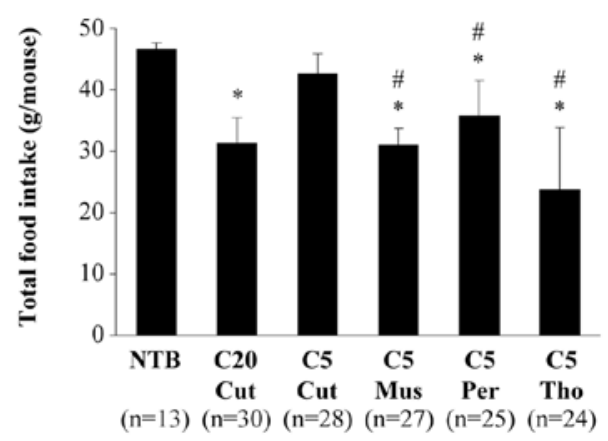

Figure 1. Changes in body weight, food and water intake, and weights of epididymal fat pad and gastrocnemius muscle. (A) Change in body weight. The body weight of NTB and C5 Cut mice did not decrease. Body weight started to decrease around the 9th day after tumor inoculation in C20 Cut, C5 Mus, C5 Per and C5 Tho mice. (B) Change in food and water intake. Mice were housed individually in closed metabolic cages, and food and water intake were calculated daily by subtracting the residues from initial amounts. (C) Weights of epididymal fat pad and gastrocnemius muscle at the end of observation period ( $\mathrm{n}=10$ ). The epididymal fat pad and gastrocnemius muscle were extirpated and weighed at 14 days after tumor inoculation. (D) Total amount of food intake during the observation period. Data represent the mean with bars indicating SD. "Significantly lower than the corresponding value for NTB at P $<0.05 .{ }^{~ " S i g n i f i c a n t l y ~}$ lower than the corresponding value for $\mathrm{C} 5 \mathrm{Cut}$ at $\mathrm{P}<0.05$. C5 Cut, mice bearing clone 5 tumor in subcutaneous tissue in the right flank; $\mathrm{C} 5 \mathrm{Mus}$, mice bearing clone 5 tumor in left gastrocnemius muscle; C5 Per, mice bearing clone 5 tumor in peritoneal cavity; C5 Tho, mice bearing clone 5 tumor in thoracic cavity; NTB, control mice bearing no tumor; C20 Cut, mice bearing clone 20 tumor in subcutaneous tissue in the right flank.

using SPSS version 11.0 for Windows (SPSS, Inc., Chicago, IL, USA). Comparisons between two groups of data were analyzed by the Mann-Whitney U test. A correlation between two groups was assessed by the Pearson correlation test. A forward selection stepwise multiple regression model for BW loss and the loss of epididymal fat pad and gastrocnemius muscle was developed using serum cytokines and chemokines with or without hormones as variables. A P-value of $<0.05$ was considered to indicate a significant difference.

\section{Results}

Body weight, food intake, and fat and muscle tissue weight. Changes in BW, food and water intake, and fat and muscle tissue weight on the 14th day after tumor inoculation and total food intake after tumor inoculation are shown in Fig. 1. BW of mice bearing clone 20 in subcutaneous tissues (C20 Cut) decreased starting at approximately 9 days after tumor inoculation and was $76.1 \%$ of those at the time of tumor inoculation. Further, food and water intake significantly decreased. The BW of C5 Cut mice did not decrease, and their amount of food and water intake decreased only slightly. However, the BW and food intake of C5 Mus mice, C5 Per mice, and C5 Tho mice significantly decreased, albeit with intergroup variation (Fig. 1A and B).

At the end of the observation period, the weights of fat and muscle tissues in $\mathrm{C} 20$ Cut were only 12 and $58.3 \%$, respectively, of those in NTB mice, while those in C5 Cut did not decrease. Relative to NTB mice, the weights of the epididymal fat pad and the gastrocnemius muscle were 28.7 and $55.4 \%$, 64.1 and $71.9 \%$, and 65.4 and $75.3 \%$ in C5 Mus, C5 Per and C5 Tho, respectively. Among mice bearing the clone 5 tumor, the weights of fat and muscle tissues were the lowest in C5 Mus; further, those in C5 Mus, C5 Per and C5 Tho were significantly lower than those in C5 Cut (Fig. 1C).

Total amount of food intake in C20 Cut was significantly lower than that of NTB. While the amount of food intake did not decrease in C5 Cut, it did significantly decrease in C5 Mus, C5 Per and C5 Tho (Fig. 1D). Although the decreased food intake was accompanied by a decrease in fat and muscle tissue, changes in these variables did not correlate with each other. Although the most prominent decrease in food intake was found in C5 Tho, their fat and muscle tissues were preserved to a greater degree than those of C5 Mus or C20 Cut.

We performed similar experiments using clone 20 cells. Clone 20 cells were inoculated either in muscle tissue, 
Table I. Peripheral blood examination.

\begin{tabular}{|c|c|c|c|c|c|c|c|c|}
\hline & $\begin{array}{l}\text { WBC } \\
\left(\mathrm{mm}^{3}\right)\end{array}$ & $\begin{array}{l}\text { Neutrophils } \\
\quad\left(\mathrm{mm}^{3}\right)\end{array}$ & $\begin{array}{c}\text { Monocytes } \\
\left(\mathrm{mm}^{3}\right)\end{array}$ & $\begin{array}{l}\text { Lymphocytes } \\
\left(\mathrm{mm}^{3}\right)\end{array}$ & $\begin{array}{c}\mathrm{RBC} \\
\left(\mathrm{x} 10^{4} / \mathrm{mm}^{3}\right)\end{array}$ & $\begin{array}{c}\mathrm{Hb} \\
(\mathrm{g} / \mathrm{dl})\end{array}$ & $\begin{array}{c}\text { Platelets } \\
\left(\mathrm{x} 10^{4} / \mathrm{mm}^{3}\right)\end{array}$ & $\begin{array}{l}\mathrm{SAA} \\
(\mathrm{mg} / \mathrm{l})\end{array}$ \\
\hline NTB & $1,571 \pm 180$ & $307 \pm 55$ & $79 \pm 28$ & $1,183 \pm 170$ & $946 \pm 56$ & $13.5 \pm 0.6$ & $81 \pm 17$ & $0.4 \pm 0.1$ \\
\hline $\begin{array}{l}\mathrm{C} 20 \\
\mathrm{Cut}\end{array}$ & $3,514 \pm 1229^{a}$ & $1,033 \pm 554^{\mathrm{a}}$ & $182 \pm 93^{\mathrm{a}}$ & $2,299 \pm 617^{\mathrm{a}}$ & $931 \pm 34$ & $13.0 \pm 0.4^{\mathrm{a}}$ & $163 \pm 36^{\mathrm{a}}$ & $463 \pm 142^{a, b}$ \\
\hline $\begin{array}{l}\text { C5 } \\
\text { Cut }\end{array}$ & $3,542 \pm 315^{\mathrm{a}}$ & $861 \pm 114^{a}$ & $305 \pm 15^{\mathrm{a}}$ & $2,497 \pm 323^{a}$ & $915 \pm 35$ & $13.2 \pm 0.5$ & $131 \pm 25^{\mathrm{a}}$ & $256 \pm 178^{a}$ \\
\hline $\begin{array}{l}\text { C5 } \\
\text { Mus }\end{array}$ & $4,928 \pm 430^{\mathrm{a}, \mathrm{b}}$ & $1,015 \pm 158^{\mathrm{a}}$ & $262 \pm 67^{a, b}$ & $3,644 \pm 420^{a, b}$ & $905 \pm 39$ & $12.6 \pm 0.5^{\mathrm{b}}$ & $182 \pm 10^{a, b}$ & $576 \pm 104^{a, b}$ \\
\hline $\begin{array}{l}\text { C5 } \\
\text { Per }\end{array}$ & $4,628 \pm 844^{\mathrm{a}, \mathrm{b}}$ & $1,171 \pm 191^{\mathrm{a}, \mathrm{b}}$ & $191 \pm 75^{\mathrm{a}}$ & $3,258 \pm 795^{\mathrm{a}, \mathrm{b}}$ & $899 \pm 18^{a}$ & $13.1 \pm 0.2^{\mathrm{a}}$ & $104 \pm 18$ & $64 \pm 59^{a, b}$ \\
\hline $\begin{array}{l}\text { C5 } \\
\text { Tho }\end{array}$ & $4,757 \pm 1429^{a, b}$ & $1,290 \pm 492^{\mathrm{a}, \mathrm{b}}$ & $206 \pm 79^{a}$ & $3,261 \pm 722^{a, b}$ & $1,061 \pm 108^{a, b}$ & $15.2 \pm 1.4^{\mathrm{a}, \mathrm{b}}$ & $108 \pm 7^{\mathrm{a}}$ & $28 \pm 37^{\mathrm{a}, \mathrm{b}}$ \\
\hline
\end{tabular}

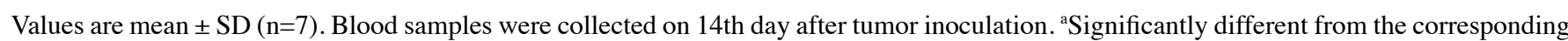
value for $\mathrm{C} 20 \mathrm{Cut}$ at $\mathrm{P}<0.05$. 'Significantly different from the corresponding value for $\mathrm{C} 5 \mathrm{Cut}$ at $\mathrm{P}<0.05$. C5 Cut, mice bearing clone 5 tumor in subcutaneous tissue in the right flank; C5 Mus, mice bearing clone 5 tumor in left gastrocnemius muscle; C5 Per, mice bearing clone 5 tumor in peritoneal cavity; C5 Tho, mice bearing clone 5 tumor in thoracic cavity; NTB, control mice bearing no tumor; C20 Cut, mice bearing clone 20 tumor in subcutaneous tissue in the right flank; WBC, white blood cells; RBC, red blood cells; Hb, hemoglobin; SAA, serum amyloid A.

Table II. The concentration of serum or plasma hormones.

\begin{tabular}{|c|c|c|c|c|c|c|c|}
\hline & \multicolumn{2}{|c|}{ Serum (ng/ml) } & \multicolumn{5}{|c|}{ Plasma (pg/ml) } \\
\hline & Insulin & Corticosterone & ACTH & Glucagon & Adrenaline & Noradrenaline & Dopamine \\
\hline NTB & 1.4 & 272.7 & 114 & 66 & 792 & 1,072 & 135 \\
\hline C20 Cut & 1.3 & 589.7 & 88.3 & 66 & 699 & 506 & 57 \\
\hline C5 Cut & 2.7 & 376.6 & 269 & 44 & 6,149 & 4,318 & 179 \\
\hline C5 Mus & 2.0 & 344.8 & 267 & 50 & 2,272 & 1,411 & 80 \\
\hline C5 Per & 0.7 & 436.2 & 205 & 47 & 1,933 & 2,699 & 262 \\
\hline C5 Tho & 1.4 & 786.4 & 43.9 & 65 & 2,048 & 4,053 & 502 \\
\hline
\end{tabular}

Mixture of serum or plasma from six mice was used for measurements. Serum corticosterone was increased in tumor-bearing mice, regardless of the presence or absence of manifestations of cancer cachexia. C5 Cut, mice bearing clone 5 tumor in subcutaneous tissue in the right flank; C5 Mus, mice bearing clone 5 tumor in left gastrocnemius muscle; C5 Per, mice bearing clone 5 tumor in peritoneal cavity; C5 Tho, mice bearing clone 5 tumor in thoracic cavity; NTB, control mice bearing no tumor; C20 Cut, mice bearing clone 20 tumor in subcutaneous tissue in the right flank; ACTH, adrenocorticotropic hormone.

peritoneal cavity, or thoracic cavity. All of these animals suffered typical cancer cachexia of greater severity and died earlier when compared with C20 Cut.

Blood analyses. When compared with NTB mice, the number of white blood cells (WBC), including neutrophils, monocytes, and lymphocytes, and platelets in the peripheral blood were increased in tumor-bearing mice irrespective of the presence or the severity of cachectic manifestations. No significant difference in peripheral blood examination except for SAA was observed between C20 Cut and C5 Cut. Among C5 groups of mice, the WBC count correlated with the mani- festations of cancer cachexia. SAA, an acute phase reactant reflecting inflammation in the body, significantly increased in C20 Cut, C5 Cut, and C5 Mus and increase to a lesser degree in C5 Per and C5 Tho, despite the fact that there was a significant increase in the WBC count in C5 Per and C5 Tho mice (Table I).

Corticosterone levels increased in tumor-bearing mice irrespective of the presence of cachectic manifestations. However, levels of other hormones, such as serum insulin, plasma glucagon, and plasma catecholamines, did not correlate with tumor inoculation or the manifestations of cancer cachexia (Table II). 
A

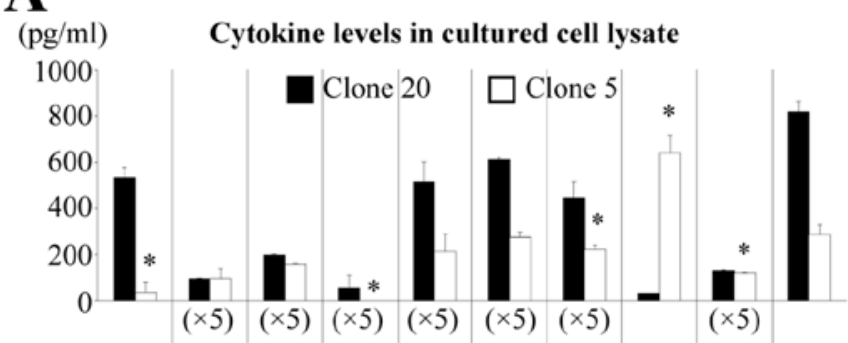

$20000 \quad$ Cytokine levels in conditioned medium

16000

12000

8000

4000

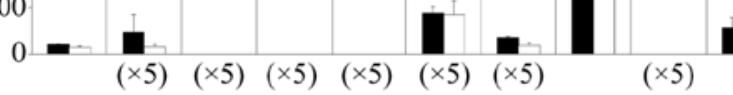

2.

B

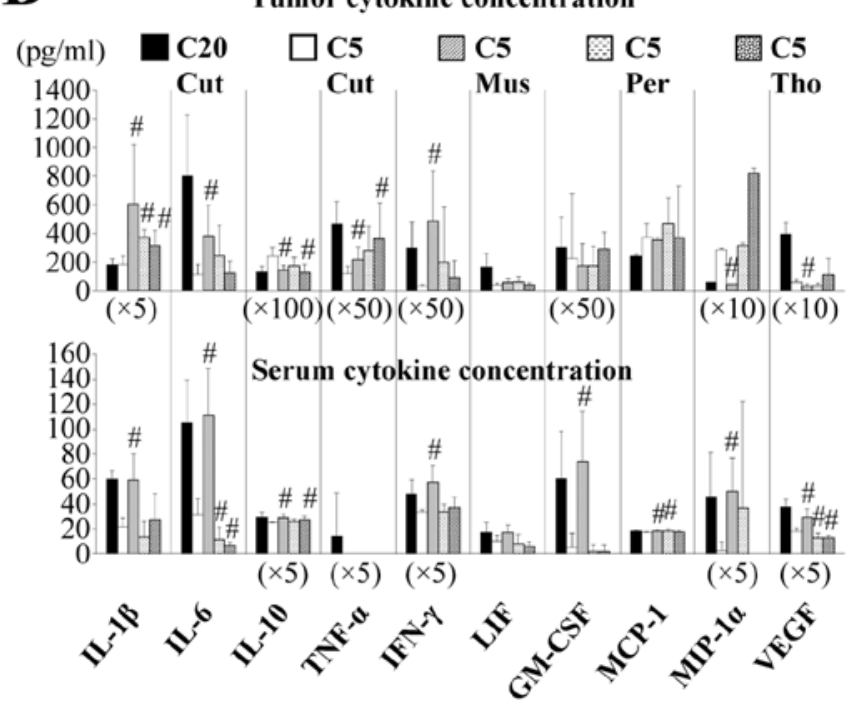

Figure 2. Concentrations of cytokines and chemokines in culture cell lysate, conditioned medium, tumor lysate and murine serum. (A) Cells $\left(1 \times 10^{6}\right)$ $(n=3)$ and its conditioned medium $(n=2)$ were analyzed. (B) Murine serum and lysates of inoculated tumor $(n=6)$. Each value represents the mean with bars indicating SD. "Significantly different from the corresponding value for $\mathrm{C} 20$ Cut at $\mathrm{P}<0.05$. "Significantly different from the corresponding value for C5 Cut at $\mathrm{P}<0.05$.

Cytokine levels. When comparing the levels of various cytokines and chemokines in the conditioned medium, no significant difference was found between clones 5 and 20 , despite the fact that the ability of these clones to induce cachexia was significantly different. In cell lysate, levels of the majority of cytokines and chemokines were higher in clone 20 cells than in clone 5 cells, while levels of MCP-1 were lower in clone 20 than in clone 5 (Fig. 2A).

Types and concentrations of cytokines and chemokines in the lysates of the inoculated tumor and in the serum of C5 Cut and C20 Cut groups did not differ significantly when compared with those in conditioned medium and culture cell lysate. Levels of these substances tended to be lower in clone $5 \mathrm{Cut}$
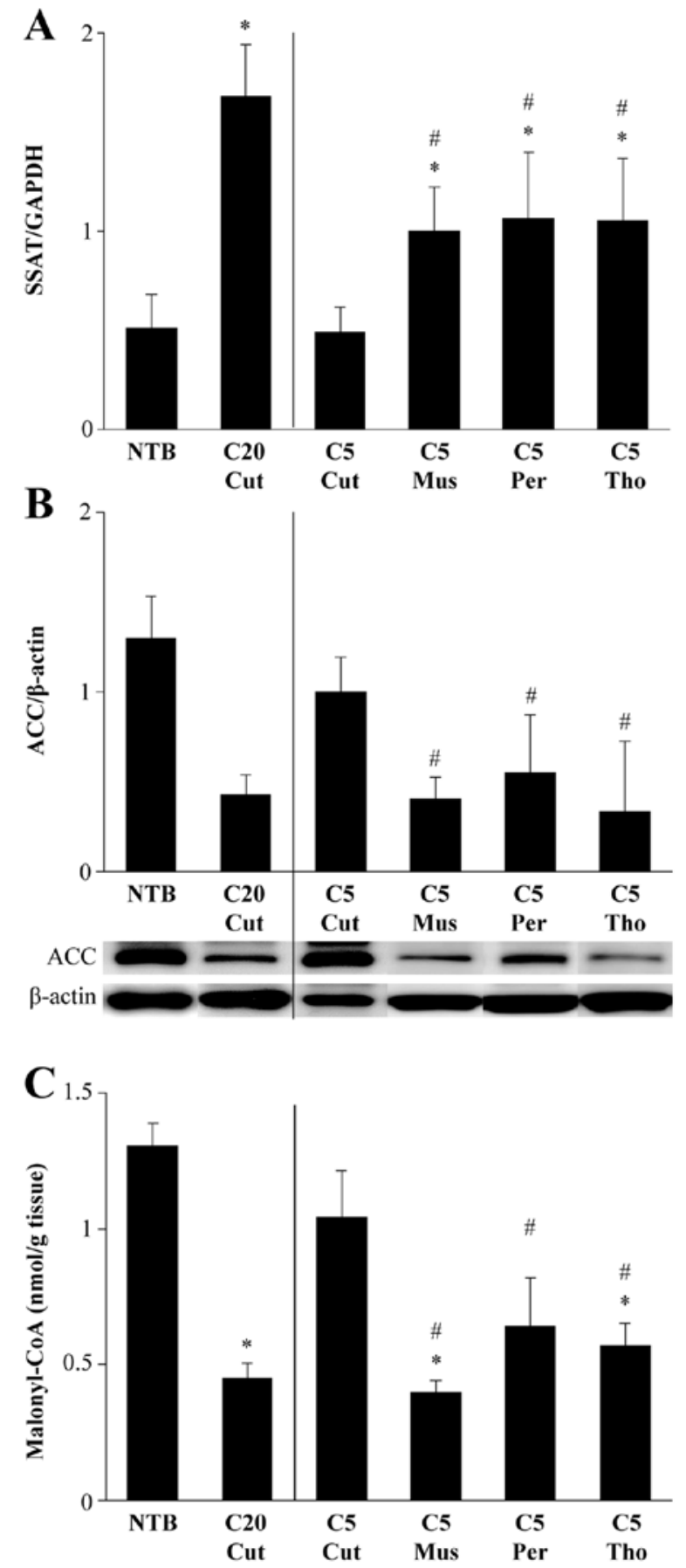

Figure 3. Levels of SSAT mRNA, ACC and malonyl-CoA. Murine liver was extirpated on day 14 after tumor inoculation and examined. (A) SSAT mRNA levels ( $n=6)$. (B) ACC levels $(n=7)$. (C) Malonyl-CoA levels. Malonyl-CoA levels in the liver $(n=6)$. Data represent the mean with bars indicating SD. "Significantly different from the corresponding value for $\mathrm{C} 20$ Cut at $\mathrm{P}<0.05$. ${ }^{\#}$ Significantly different from the corresponding value for $\mathrm{C} 5 \mathrm{Cut}$ at $\mathrm{P}<0.05$.

than in clone 20 Cut, except for MCP-1 and MIP-1 $\alpha$. Further, levels of IL-1 $\beta$, IL-6, TNF- $\alpha$ and IFN- $\gamma$ were elevated in tumor lysates of C5 Mus, C5 Per, and C5 Tho when compared with C5 Cut. Although serum IL-1 $\beta$, IL-6, IFN- $\gamma$, and GM-CSF were increased in C20 Cut and C5 Mus, no such increases were found in C5 Per and C5 Tho (Fig. 2B).

In order to identify factors involved in the induction of cancer cachexia, the mean serum levels of cytokine and chemokines that affect BW and the weights of epididymal fat 


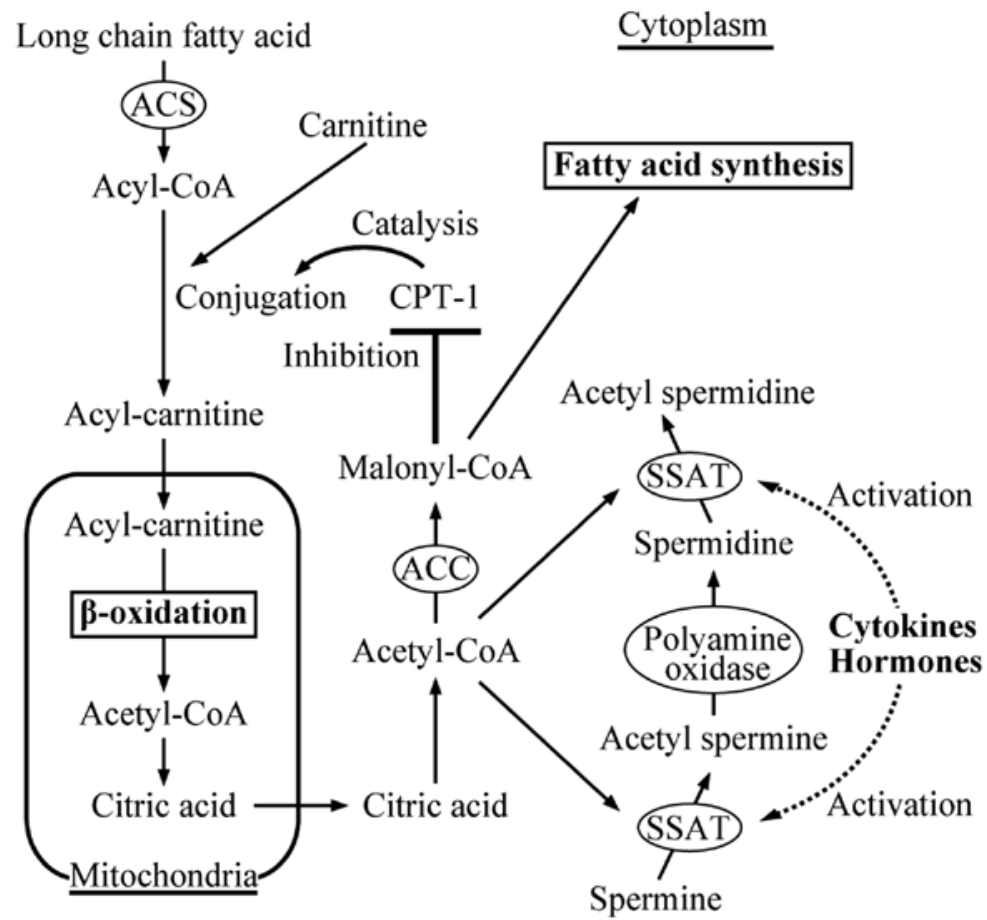

Figure 4. Metabolic scheme of fatty acid oxidation in the liver. ACS, acyl-CoA synthetase; SSAT, spermidine/spermine N-1 acetyl transferase; ACC, acetylCoA carboxylase; CPT-1, carnitine palmitoyltransferase 1; acetyl-CoA, acetyl coenzyme A; malonyl-CoA, malonyl coenzyme A.

pad and gastrocnemius muscle were assessed in a stepwise multiple regression model using the forward selection method among the four groups of mice bearing clone 5 (C5 Cut, C5 Mus, C5 Per and C5 Tho) with NTB mice. Significant independent variables included IL-10 $(\mathrm{R}=-0.911, \mathrm{P}=0.032)$ for $\mathrm{BW}$; IL-10 ( $\mathrm{R}=-0.849, \mathrm{P}=0.004), \mathrm{MIP}-1 \alpha(\mathrm{R}=-0.403, \mathrm{P}=0.006)$, and IFN- $\gamma(\mathrm{R}=0.159, \mathrm{P}=0.027)$ for the weight of epididymal fat pad; and IL-10 $(\mathrm{R}=-0.701, \mathrm{P}=0.004)$ and MCP-1 $(\mathrm{R}=-0.379$, $\mathrm{P}=0.012$ ) for the weight of gastrocnemius muscle. When levels of hormones were added to the analysis, the results were the same, except that dopamine $(\mathrm{R}=-0.044, \mathrm{P}=0.011)$ was identified as a significant independent variable for the weight of gastrocnemius muscle.

SSAT expression, acetyl-CoA carboxylase levels, and malonylCoA levels. Levels of SSAT mRNA relative to GAPDH mRNA were significantly increased in cachectic mice but not in the C5 Cut group. SSAT mRNA levels were 3-fold higher in C20 Cut than in NTB, and SSAT mRNA levels were 2-times higher in C5 Mus, C5 Per and C5 Tho than in NTB (Fig. 3A).

The amounts of ACC were corrected against $\beta$-actin. Tumor inoculation resulted in a decrease in ACC levels irrespective of the presence of cachectic manifestations. However, this decrease was augmented when mice were suffering from cancer cachexia. Relative to NTB groups, ACC levels were 33, 31, 43 and 26\% in C20 Cut, C5 Mus, C5 Per and C5 Tho, respectively (Fig. 3B).

The amounts of hepatic malonyl-CoA were not decreased in non-cachectic C5 Cut mice but they were significantly decreased in $\mathrm{C} 20$ Cut mice ( $\mathrm{P}=0.004$ vs. NTB). Relative to NTB mice, the amounts of hepatic malonyl-CoA concentrations in C5 Mus, C5 Per, and C5 Tho were 30.5, 49.2 and $43.5 \%$, respectively, which were significantly lower than that in C5 Cut mice ( $\mathrm{P}=0.004$ vs. $\mathrm{C} 5$ Mus; $\mathrm{P}=0.010$ vs. C5 Per; $\mathrm{P}=0.004$ vs. C5 Tho) (Fig. 3C).

SSAT is activated by cytokines and hormones, and SSAT activation and resultant decreases in malonyl-CoA concentrations are involved in the mechanism of lipolysis, a typical manifestation of cancer cachexia (Fig. 4). However, when comparing among mice bearing the clone 5 tumor (C5 Cut, C5 Mus, C5 Per and C5 Tho) with or without NTB, there was no correlation between SSAT/GAPDH and the weight of epididymal fat pad (with NTB: $\mathrm{R}=-0.357, \mathrm{P}=0.052, \mathrm{n}=30$; without NTB: $\mathrm{R}=-0.315, \mathrm{P}=0.133, \mathrm{n}=24$ ) (Fig. 5A). However, there was an inverse correlation between SSAT/GAPDH and the weight of epididymal fat pad when the C20 Cut group of mice was added to the analysis $(\mathrm{R}=-0.588, \mathrm{P}<0.001, \mathrm{n}=36)$ (Fig. 5B). There was a close positive correlation between malonyl-CoA levels and the weight of epididymal fat pad in mice bearing clone 5 tumor, whether or not the NTB group of mice was added to the analysis (NTB mice included: $\mathrm{R}=0.415$, $\mathrm{P}=0.022, \mathrm{n}=30$; NTB mice not included $\mathrm{R}=0.789, \mathrm{P}<0.001$, $\mathrm{n}=24$ ) (Fig. 5C). Further, there was a close positive correlation between malonyl-CoA levels and fat weights among all groups of animals ( $\mathrm{R}=0.509, \mathrm{P}=0.002, \mathrm{n}=36)$ (Fig. 5D).

Macroscopic, histological, and immunohistochemical findings of transplanted tumors. In some animals in the C5 Tho and C5 Per groups, tumor invasion to the heart and large vessels was observed. However, such animals died at a very early stage and we excluded mice from the study analysis when apparent tumor invasion to important organs (e.g., lung, heart, major vessels, liver, kidney, intestines) was found macroscopically. Generally, several lumps of clone 5 tumor were found to be disseminated in the thoracic and peritoneal cavities. Histological evaluation revealed no significant differ- 
A
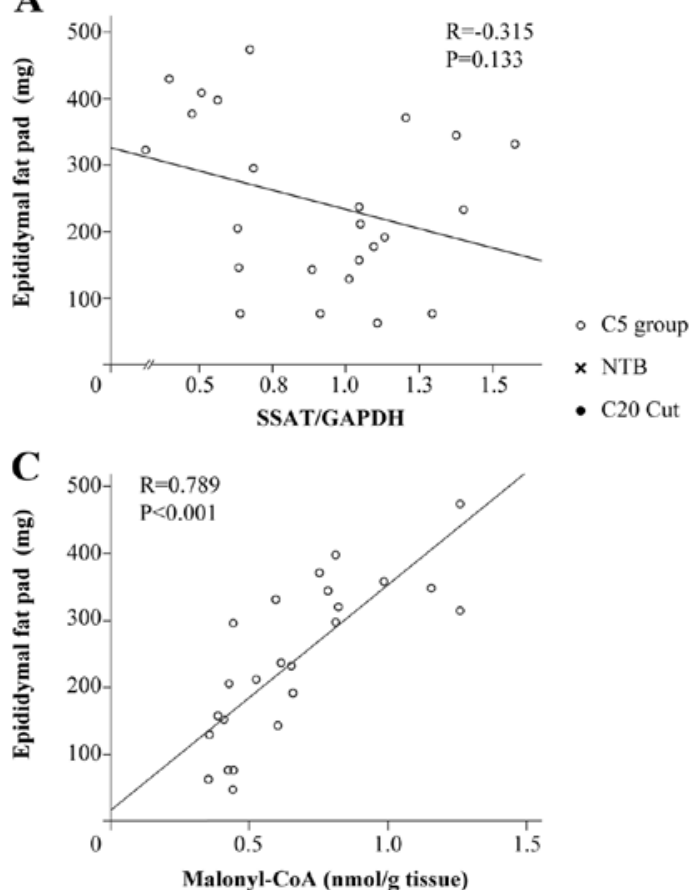

B

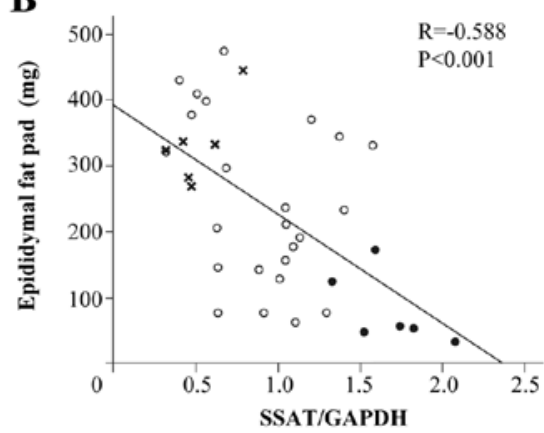

D

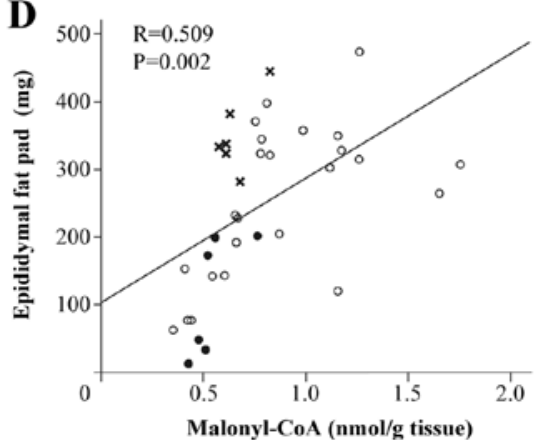

Figure 5. Correlations between epididymal fat weight and SSAT-mRNA levels and between epididymal fat weight and malonyl CoA. (A) Correlations between fat weight and SSAT among mice bearing clone 5 tumor $(n=24)$. (B) Correlations between fat weight and SSAT among all groups of mice, including NTB and C20 Cut ( $\mathrm{n}=36)$. (C) Correlations between fat weight and malonyl-CoA among mice bearing clone 5 tumor $(\mathrm{n}=24)$. (D) Correlations between fat weight and malonyl-CoA among all groups of mice, including NTB and C20 Cut $(n=36)$.
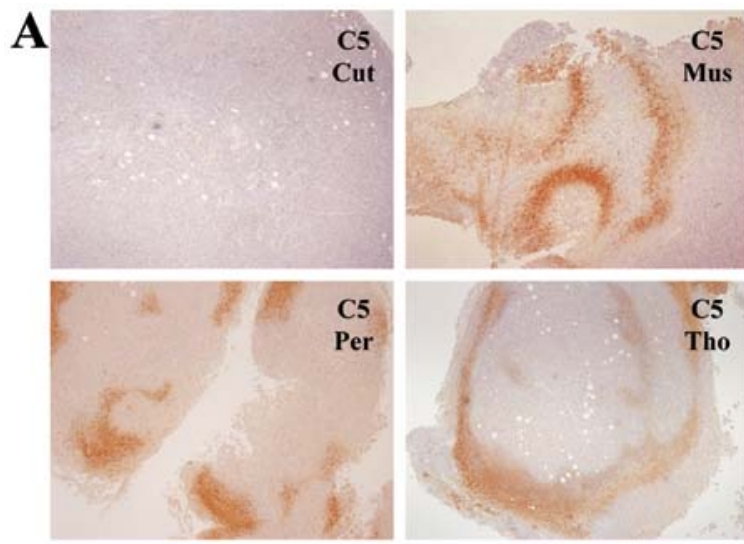

\section{B}

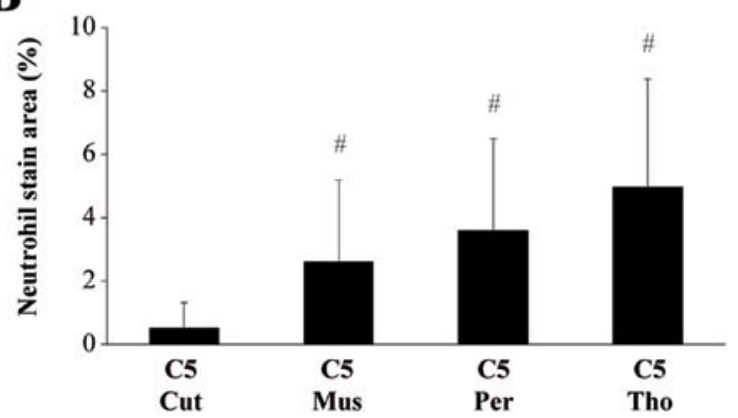

Figure 6. Pathological findings of inoculated tumors. (A) Immunohistopathological findings of neutrophils. There is massive neutrophil infiltration in clone 5 tumors inoculated either in muscle (C5 Mus), the peritoneal cavity (C5 Per), or the thoracic cavity (C5 Tho), while no such findings are present in the tumor in subcutaneous tissue (C5 Cut). (B) The quantitative assay for immunohistochemistry was performed using Image $J$ software $(n=6)$. Data represent the mean with bars indicating SD. "Significantly higher than those of $\mathrm{C} 5$ Cut at $\mathrm{P}<0.05$. ence in morphology when comparing tumors from different C5 groups (C5 Cut, C5 Mus, C5 Per, and C5 Tho).

Immunohistochemical examination showed differences in the amount of neutrophils, but not macrophages, among groups of mice bearing the clone 5 tumor. Neutrophils in tumors of C5 Cut and C20 Cut were not significant increased. However, a significantly large amount of neutrophil infiltration was found in tumors of the C5 Mus, C5 Per, and C5 Tho groups (Fig. 6).

\section{Discussion}

The present study showed that host factors are important for the induction of cancer cachexia. Use of the clone 5 tumor, which was established from a single cell in colon 26 adenocarcinoma, obviates the effect of selection of a tumor cell clone by the host's immune system, thereby facilitating experimental investigation of host factors in the present study. Indeed, inoculation of the clone 5 tumor does not result in inoculation site-dependent differences in the composition of cell clones that can otherwise be seen in other animal models where tumors were composed of many cell clones (13-15).

Levels of cytokines and chemokines in the inoculated tumor and levels of cytokines and chemokines in murine serum levels differ significantly depending on the inoculation site. Therefore, manifestations observed in the present animal model can be considered to be due mainly to a difference in the host reaction against the tumor. In addition, because these mice did not have any apparent immune or endocrine defects, the interactions between tumor and host in the present study likely reflected those seen in cancer patients. Indeed, the relationship between cachexia manifestation and serum cytokine 
levels among C5 groups was similar to that seen in human cancer cachexia, in which serum IL-10, but not other proinflammatory cytokines, is correlated with the manifestations of cancer cachexia (22-24). In the present study, only IL-10, but not IL-1 $\beta$, IL-6, or TNF- $\alpha$, had a negative correlation with $\mathrm{BW}$ and the weights of skeletal muscle and storage fat, which contradicts findings from other studies $(9,10,25-27)$.

We could not elucidate a single factor or narrow down a few factors, that play a pivotal role in the induction of cancer cachexia and should therefore be targeted for the treatment of cancer cachexia. However, malonyl-CoA seemed to be a good marker of cancer cachexia, and its preservation might be a therapeutic strategy for cancer cachexia, because the weight of storage fat in mice correlated with the amount of malonyl$\mathrm{CoA}$ in the liver. Malonyl-CoA, converted from acetyl-CoA by ACC, is a substrate of fatty acid synthesis (28). In addition, malonyl-CoA controls the uptake of mitochondrial fatty acid through allosteric inhibition of carnitine palmitoyltransferase 1 (CPT-1), the enzyme catalyzing the first committed step in mitochondrial fatty acid oxidation (29). Therefore, a decrease in malonyl-CoA resulted in decreased fatty acid synthesis and accelerates lipolysis via activation of CPT-1 and ketogenesis (30). The amount of malonyl-CoA is controlled by several factors, such as the amount of its precursor (acetyl-CoA) and the activities of ACC, malonyl-CoA decarboxylase, and SSAT $(19,31)$. SSAT overexpression provokes symptoms similar to cachexia in animals (31), and several cytokines, hormones, natural substances, and stress are known to stimulate SSAT (32-37). The continuous SSAT activation leads to an increased demand for acetyl-CoA (a co-factor of SSAT), thereby restricting conversion of acetyl-CoA to malonyl-CoA. However, among mice bearing the clone 5 tumor, SSAT mRNA levels did not correlate with the severity of cachectic manifestations. These observations suggest that some other factors that lead to a decrease in malonyl CoA levels likely play a role in the induction of cancer cachexia.

Recent clinical reports suggest that an increase in neutrophils and neutrophil infiltration to the tumor are associated with poor outcomes and an increasing severity of cachexia manifestations (38-42). In animal models, although circulating GM-CSF levels were not necessarily increased in cachectic mice, an increase in peripheral blood WBC and neutrophils correlated with cachectic manifestations of mice bearing the clone 5 tumor. The involvement of neutrophil is supported by immunohistochemical findings, because neutrophil infiltration was abundant in clone 5 tumors of mice suffering from cancer cachexia. We previously demonstrated that the suppression of granulocyte differentiation by the enhancement of erythrocyte production results in an attenuation of the manifestations of cancer cachexia (12). However, the grade of neutrophil infiltration was not necessarily accompanied by a change in SAA levels (as an indicator of systemic inflammation) or a change in the serum levels of cytokines and chemokines. These must be dependent on the specific environment of tissues and organs in which the tumor grows.

In conclusion, the present study suggests that host factors and host-tumor interactions are very important for the induction of cancer cachexia. Further, liver malonyl-CoA likely plays an important role in cancer cachexia. Finally, the animal model used in the present study appears to be suitable for the investigation of the mechanisms involved in cachexia of cancer patients.

\section{Acknowledgements}

This study was supported by Ms. Tomomi Kaku, Department of Clinical Laboratory Medicine, Jichi Medical University, Tochigi, Japan, and technical experts of Veritas Corp. in Tokyo, Japan.

\section{References}

1. Madeddu C, Maccio A and Mantovani G: Multitargeted treatment of cancer cachexia. Crit Rev Oncog 17: 305-314, 2012.

2. Honors MA and Kinzig KP: Characterization of the Yoshida sarcoma: a model of cancer cachexia. Support Care Cancer 21: 2687-2694, 2013

3. Dewys WD, Begg C, Lavin PT, et al: Prognostic effect of weight loss prior to chemotherapy in cancer patients. Eastern Cooperative Oncology Group. Am J Med 69: 491-497, 1980.

4. Tisdale MJ: Mechanisms of cancer cachexia. Physiol Rev 89: 381-410, 2009.

5. Fearon KC, Glass DJ and Guttridge DC: Cancer cachexia: mediators, signaling, and metabolic pathways. Cell Metab 16: 153-166, 2012.

6. Tisdale MJ: Are tumoral factors responsible for host tissue wasting in cancer cachexia? Future Oncol 6: 503-513, 2010

7. Rebeca R, Bracht L, Noleto GR, et al: Production of cachexia mediators by Walker 256 cells from ascitic tumors. Cell Biochem Funct 26: 731-738, 2008.

8. Tisdale MJ: Cachexia in cancer patients. Nat Rev Cancer 2: $862-871,2002$

9. Soda K, Kawakami M, Kashii A and Miyata M: Characterization of mice bearing subclones of colon 26 adenocarcinoma disqualifies interleukin-6 as the sole inducer of cachexia. Jpn J Cancer Res 85: 1124-1130, 1994.

10. Soda K, Kawakami M, Kashii A and Miyata M: Manifestations of cancer cachexia induced by colon 26 adenocarcinoma are not fully ascribable to interleukin-6. Int J Cancer 62: 332-336, 1995.

11. Soda K, Kawakami M, Takagi S, Kashii A and Miyata M: Splenectomy before tumor inoculation prolongs the survival time of cachectic mice. Cancer Immunol Immunother 41: 203-209, 1995.

12. Kanzaki M, Soda K, Gin PT, Kai T, Konishi F and Kawakami M: Erythropoietin attenuates cachectic events and decreases production of interleukin-6, a cachexia-inducing cytokine. Cytokine 32: 234-239, 2005.

13. Matsumoto T, Fujimoto-Ouchi K, Tamura S, Tanaka Y and Ishitsuka H: Tumour inoculation site-dependent induction of cachexia in mice bearing colon 26 carcinoma. Br J Cancer 79: 764-769, 1999.

14. Giavazzi R, Campbell DE, Jessup JM, Cleary K and Fidler IJ: Metastatic behavior of tumor cells isolated from primary and metastatic human colorectal carcinomas implanted into different sites in nude mice. Cancer Res 46: 1928-1933, 1986.

15. Morikawa K, Walker SM, Nakajima M, Pathak S, Jessup JM and Fidler IJ: Influence of organ environment on the growth, selection, and metastasis of human colon carcinoma cells in nude mice. Cancer Res 48: 6863-6871, 1988.

16. Fujimoto-Ouchi K, Tamura S, Mori K, Tanaka Y and Ishitsuka H: Establishment and characterization of cachexia-inducing and -non-inducing clones of murine colon 26 carcinoma. Int J Cancer 61: 522-528, 1995.

17. Tsuchiya H, Sato J, Tsuda H, et al: Serum amyloid A upsurge precedes standard biomarkers of hepatotoxicity in ritodrineinjected mice. Toxicology 305: 79-88, 2013.

18. Yamada T, Fukuda T, Wada A and Itoh Y: Monoclonal antibodybased sensitive enzyme-linked immunosorbent assay for murine serum amyloid A. J Immunoassay 20: 223-235, 1999.

19. Celik A, Kano Y, Tsujinaka S, et al: Decrease in malonyl-CoA and its background metabolic alterations in murine model of cancer cachexia. Oncol Rep 21: 1105-1111, 2009.

20. Takamura Y, Kitayama Y, Arakawa A, Yamanaka S, Tosaki M and Ogawa Y: Malonyl-CoA: acetyl-CoA cycling. A new micromethod for determination of acyl-CoAs with malonate decarboxylase. Biochim Biophys Acta 834: 1-7, 1985. 
21. Kaczmarek E, Górna A and Majewski P: Techniques of image analysis for quantitative immunohistochemistry. Rocz Akad Med Bialymst 49 (Suppl 1): 155-158, 2004.

22. Ebrahimi B, Tucker SL, Li DH, Abbruzzese JL and Kurzrock R: Cytokines in pancreatic carcinoma - correlation with phenotypic characteristics and prognosis. Cancer 101: 2727-2736, 2004.

23. Shibata M, Nezu T, Takekawa M, et al: Serum levels of interleukin-10 and interleukin-12 in patients with colorectal cancer. Ann NY Acad Sci 795: 410-412, 1996.

24. Lira FS, Rosa JC, Zanchi NE, et al: Regulation of inflammation in the adipose tissue in cancer cachexia: effect of exercise. Cell Biochem Funct 27: 71-75, 2009.

25. Strassmann G, Fong M, Kenney JS and Jacob CO: Evidence for the involvement of interleukin 6 in experimental cancer cachexia. J Clin Invest 89: 1681-1684, 1992.

26. Greenberg AS, Nordan RP, McIntosh J, Calvo JC, Scow RO and Jablons D: Interleukin 6 reduces lipoprotein lipase activity in adipose tissue of mice in vivo and in 3T3-L1 adipocytes: a possible role for interleukin 6 in cancer cachexia. Cancer Res 52: 4113-4116, 1992.

27. Johnen H, Lin S, Kuffner T, et al: Tumor-induced anorexia and weight loss are mediated by the TGF-beta superfamily cytokine MIC-1. Nat Med 13: 1333-1340, 2007.

28. Harwood HJ: Treating the metabolic syndrome: acetyl-CoA carboxylase inhibition. Expert Opin Ther Targets 9: 267-281, 2005.

29. McGarry JD and Brown NF: The mitochondrial carnitine palmitoyltransferase system. From concept to molecular analysis. Eur J Biochem 244: 1-14, 1997.

30. Foster DW: The role of the carnitine system in human metabolism. Ann NY Acad Sci 1033: 1-16, 2004.

31. Jell J, Merali S, Hensen ML, et al: Genetically altered expression of spermidine/spermine N1-acetyltransferase affects fat metabolism in mice via acetyl-CoA. J Biol Chem 282: 84048413,2007

32. Casero RA and Pegg AE: Spermidine/spermine N1-acetyltransferase - the turning point in polyamine metabolism. FASEB J 7: 653-661, 1993.
33. Desiderio MA, Pogliaghi G and Dansi P: Regulation of spermidine/spermine N1-acetyltransferase expression by cytokines and polyamines in human hepatocarcinoma cells (HepG2). J Cell Physiol 174: 125-134, 1998.

34. Green ML, Chung TE, Reed KL, et al: Paracrine inducers of uterine endometrial spermidine/spermine N1-acetyltransferase gene expression during early pregnancy in the pig. Biol Reprod 59: 1251-1258, 1998

35. Rodriguez-Sallaberry C, Simmen FA and Simmen RC: Polyamine- and insulin-like growth factor-I-mediated proliferation of porcine uterine endometrial cells: a potential role for spermidine/spermine $\mathrm{N}(1)$-acetyltransferase during periimplantation. Biol Reprod 65: 587-594, 2001.

36. Huang YL and Taylor MW: Induction of spermidine/spermine N1-acetyltransferase by interferon type I in cells of hematopoietic origin. J Interferon Cytokine Res 18: 337-344, 1998.

37. Babbar N, Hacker A, Huang Y and Casero RA: Tumor necrosis factor alpha induces spermidine/spermine N-1-acetyltransferase through nuclear factor kappa B in non-small cell lung cancer cells. J Biol Chem 281: 24182-24192, 2006.

38. McMillan DC: Systemic inflammation, nutritional status and survival in patients with cancer. Curr Opin Clin Nutr Metab Care 12: 223-226, 2009

39. McMillan DC: The systemic inflammation-based Glasgow Prognostic Score: a decade of experience in patients with cancer. Cancer Treat Rev 39: 534-540, 2013.

40. Zahorec R: Ratio of neutrophil to lymphocyte counts - rapid and simple parameter of systemic inflammation and stress in critically ill. Bratisl Lek Listy 102: 5-14, 2001.

41. Donskov F: Immunomonitoring and prognostic relevance of neutrophils in clinical trials. Semin Cancer Biol 23: 200-207, 2013.

42. Dumitru CA, Moses K, Trellakis S, Lang S and Brandau S: Neutrophils and granulocytic myeloid-derived suppressor cells: immunophenotyping, cell biology and clinical relevance in human oncology. Cancer Immunol Immunother 61: 1155-1167, 2012. 